\title{
Storytelling, Culture, and Indigenous Methodology
}

\author{
Adrienne S. Chan
}

\begin{abstract}
This chapter examines the role of Indigenous storytelling as a method and an epistemology, with an explicit connection to land-based work, community, and a sustained a process for healing with Indigenous peoples. The chapter describes important personal insights for the researcher, and the development of a better understanding of relationships with youth and young adults within the context of the storytelling process. Storytelling can be a way of reclaiming identity and reclaiming one's own stories, rather than being defined and storied by hegemonic forces.

Storytelling has been valued in traditional ways of knowing in Indigenous cultures and is seen as a primary means to pass on knowledge over generations. Through research on the resilience of Indigenous youth and their relationship to culture, identity, and land, there are stories created and recreated. The research is the story and it makes a difference to how Indigenous youth and adults learn experience their lives. The particular focus of this work is with Indigenous youth, young adults, and their ability to remain healthy and hopeful, rather than despairing, and at a loss regarding identity and belonging.
\end{abstract}

\section{Keywords}

Indigenous peoples - storytelling - land-based - identity - healing

\section{Introduction}

I am very proud to be Indigenous. You know, when I was growing up, I was not very proud, because I thought being First Nations, you had no culture and no language. And I grew up with that because my parents were descendants of Residential Schools, so I struggled with that. So, I was a woman who lived off the land. I had to learn to hunt and fish and grow food for my family .... I learned at a very young age what it took to live off the land .... (YCPO7) 
In Canada, Indigenous peoples have valued storytelling for centuries, as a way of conveying history and knowledge through their families and communities. The young woman, quoted above, shared her thoughts on culture and living off the land - which was common to the narratives that we heard in our research with communities. Storytelling was, and is, foundational to a way of life and has occurred over many generations as a way of sharing.

In this chapter, I describe a project working with Indigenous youth and young adults, whereby storytelling was an element of regaining a sense of belonging and identity, connection to the land, and a sustained a process for healing. I also describe Indigenous methodologies and how working with stories brought important personal insights and fostered my own development as a researcher working within a community.

Storytelling is a process of reclaiming the story, to own the story, rather than be defined or storied by others. Colonisers have historically told and shaped the stories of Indigenous peoples. The young woman, quoted above, tells her story, in her own terms, as a point of reclaiming her pride in being an Indigenous woman. As researchers, working with Indigenous youth and young adults, our task is facilitating the process of stories, and how individuals shape new narratives in their own way, based on their sense of culture. This also means that, as researchers, we learn about the storytelling process. As researchers, we do not own these stories, they are owned by the narrators. Storytelling, in this way, is a cultural and political act.

\section{$2 \quad$ The Storyteller and I}

My father was a great storyteller, but I was unable to think about the meaning of his stories until I was an adult; then I began to understand that his stories were about life learning. He used metaphors where meanings were not immediately apparent to me. For example, he used to talk about a bundle of chopsticks that could not be broken if they were held together. This story was about strength in numbers and unity. The chopstick is thin, often made of bamboo, and fragile. This type of metaphor is used to shape values and cultural learning in familiar places, everyday discourse, at home, and in the community.

Metaphors are ways of understanding social and educational contexts and help us to understand lived experiences, when the "existing language is not capable of adequately describing the topic term or the listener does not possess the necessary language to understand the topic term" (Jensen, 2006, p. 9). With the image of the chopsticks in a bundle, my father was, in his own way, using a metaphoric pedagogy, because we knew what he meant as family unity. 
When I started this journey, I thought that I was not a natural storyteller, and yet I was surrounded by stories from my family. The process of storytelling was a path of discovery and learning activated during my doctoral studies, when I was asked: "What was the journey that brought you here?" In order to articulate the story, I had to trust that I could find the words, and work with the knowledge that storytelling already had a place in my history. In this process, I found that sense of the story through the support of my family, mentors, and colleagues. This connection is about the relationships of past, present, and future. Relationships are always there, in the research process and in storytelling. My understanding of storytelling has expanded through my current research, where stories are about experiences and learning, and also the place to teach a living history, about lived lives, and to make "ancestral and contemporary connections to place" (Corntassel, Chaw-win-is, \& T'lakwadzi, 20o9, p. 137), which may include cultural, community, land, and historical sites.

In this chapter, I describe how my thinking evolved about storytelling, and how the research team engaged in storytelling from our different backgrounds. We consider our relationships working with Indigenous youth, young adults, their stories, and their identity. These relationships with story are different starting points in the research process and a place to re-imagine open ways to relate to culture and belonging. One of the lessons learned was to incorporate the spirit and the heart while telling a story (Archibald, 2018), being aware that the process of telling engages us in connection to family, to heart, and to what matters. This makes the story alive and true. A fragment of such an embodied story is enough to trigger another story because of this connection to the whole and the feelings it evokes. The process is an ongoing one; there is no necessary logic, coherence, or ending to a story. It is there to teach something; it is more than recounting events or feelings to another person. The process touches others, in their bodies and souls, and it transforms the narrator as well.

Moreover, the storytelling process can be a way of reclaiming identity and the story, rather than being defined and storied by hegemonic forces. Colonialism dispossessed the Indigenous peoples of their culture and disconnected them from their ecologies: land, language, and community (Alfred, 2009). The result was social and political alienation and turmoil. Therefore, storytelling is part of healing and a means for renewed engagement with one's own roots.

For the purposes of the chapter, I use the term Indigenous; some of the narrators refer to themselves as First Nations or Aboriginal. The chapter is limited by the complexity and broad description of the storytelling process, and the important context of Indigenous peoples and storytelling. Furthermore, the chapter is written keeping the Indigenous youth and community at the forefront. From my positionality, I am aware of the potential coloniality and power dynamics of myself as the researcher. 


\section{Indigenous Methodology and Storytelling}

Indigenous storytelling is connected to our homelands and is crucial to the cultural and political resurgence of Indigenous nations. (Corntassel, Chaw-win-is, \& T'lakwadzi, 2009, p. 137)

The purpose of the research was to understand and build resilience with Indigenous youth as a means of suicide prevention. A key element to the research was sharing and storytelling. The research documents what interventions were useful in keeping youth, and young adults, healthy, while keeping the integrity of Indigenous perspectives and principles. The research team, comprising Indigenous and non-Indigenous researchers and community collaborators, worked with land-based activities in the Indigenous communities. Youth suicide, health and mental health issues are indicators. At the same time, the project meant thinking differently about suicide, health, resilience, and mental wellness by engaging in Indigenous perspectives. Ultimately the research team worked towards fostering and maintaining wellness in a cultural context, with the explicit understanding that community health agencies and Indigenous elders and chiefs will participate fully as partners. Indeed, Indigenous communities set priorities for us.

This research is grounded in Indigenous methods (Kovach, 2009; Smith, 2012; Wilson, 2008), which means we are working with Indigenous peoples rather than on them. We are aware of orientalism (Said, 1978) and the danger of exoticising Indigenous cultures or claiming objectivity. Kovach (2009) suggests two principles in taking Indigenous methods: first, the approach cannot be seen as taking something away from Indigenous peoples, and is meant to be "accountable to Indigenous community standards on research so as to honour the tribal worldview" (Kovach, 2009, p. 29); second, researchers recognise that Western and Indigenous epistemologies are different in philosophy, ideology, and method. These differences challenge both Indigenous and non-Indigenous scholars and researchers to find a balance and work with insider-outsider relationships to the research.

Storytelling is part of Indigenous methodology: "Stories hold within them knowledges while simultaneously signifying relationships. In oral tradition, stories can never be decontextualised from the teller" (Kovach, 2009, p. 94). Smith situates this within learning: "stories, values, practices and ways of knowing continue to inform Indigenous pedagogies" (2012, p. 15).

To understand and use Indigenous methods, we are aware of our colonial history, the need to decolonise ourselves as researchers (McAslin, 2005; Smith, 2012), and to engage in re-learning and new learning. This means our assumptions and values are challenged. It has been troubling and powerful for me to 
learn more about myself, my challenges, and what I need to do in order to work with integrity as a researcher (Chan, 2017). An example of this, is with the struggle I have when some Indigenous researchers welcome me as an ally, while others reject me, as bearing colonialism and hegemony. As a non-Indigenous person, I must own the part I play, between colonialism and efforts to decolonise.

Indigenous epistemologies are relational and ecological; there is no single individual, or mind, self-determined, separated, and autonomous from its ecology, which for us means land, community, and ancestors. A recognition of these relationships is key to research work, which is about relationships, ceremony, and forms of cultural practice (Wilson, 2008). Therefore, by working with Indigenous peoples we are challenged in our deepest presuppositions, as we were educated in Western countries and traditions. Using Indigenous research methods, we intend to make a difference in people's lives and communities; we are not merely extracting or analysing information, but we work with the members of the community on community driven issues. We aim to decolonise the past and address the future. The development of trusting relationships with elders and youth requires us to meet regularly to work through and discuss the aims of our work together.

\section{Indigenous Youth, Ecology, and Story}

I was just thinking, what is not a connection to the land? Because everything that we are, is the land, and that's who we are. Whatever food is there, wherever we are, is the food that's there for us; whatever medicine is there, is the medicines that we use. (YCPO8)

This young man speaks of the land and the connection to living. Most of our youths live in what is known as Stó:lō Nation territory, and they entered the project through our communication with community members. Stó:lō people are the 'people of the river', and storytelling is a tradition. Storytelling was used to document the impact of our land-based activities. Over more than three years, we are actively engaging with young adults and youth; many of them were part of youth groups in their community. They may also be invited to participate by elders, parents, or youth workers, who work regularly with youth. The young people were not necessarily 'at risk', although their communities had been affected by youth suicide. The research team proposed to explore with them the cultural narratives and forces that shaped their lives. The young people shared with us what they wanted to do, in order to reconnect with the land, their culture, and the elders. 
Youth and young adults participated in many activities, with ongoing learning. We saw changes in them as they grew more comfortable with certain land activities, and more open to talk and tell their stories. We came to understand that storytelling was pivotal to the process and felt a need to ascribe value to it. So, we engaged as a team in understanding storytelling and the nature of story (Archibald, 2008).

As a team, we were going on hikes and 'on land' activities with youths, learning about such things as the importance of the cedar tree, or Indigenous medicines and plants, and the meaning of cultural practices and heritage. All the activities were led by community partners and youth workers rather than researchers. In this regard, we were co-learners with the youth. Activities later expanded to drum making, drumming, working with cedar wood, storytelling from elders, and ceremonies regarding fishing. There is, for example, a salmon ceremony that involves a freshly caught salmon. This represents the harvest (in Western terms) and is considered a recognition of the gift of salmon from the river. Fishing is fundamental to the survival of Indigenous communities in the Pacific Northwest of North America.

Youths would often reflect on the activities they participated in, offering their thoughts about the land and their relationship to it:

I, too, am getting better at being connected with the land, in the sense of learning the oral history, and the teachings that are connected with the land, because I don't know it. I've been told those stories many times, listened to an elder, and heard the stories. (YCP14)

These reflections came out regularly during our talking circles, a traditional oral practice. The circle is a cultural element that the youth are familiar with and participate in at their home communities. In working with the youths, they were aware of our need to 'document' the process. However, no notes were taken in these meetings. After our meetings and activities, the research team would journal our reflections.

We document in a reflective way since we are aware that after colonialism, fears of cultural appropriation are real. Stories are owned by the youths. We did not take the stories from them; they were shared with their permission. This was discussed at the outset of our work with the youth. Even when they shared their stories with us, they had to decide and state if they wanted to share them beyond the group. As well, the discussions were led by an Indigenous facilitator, recognised as part of the community, and with an established trusting relationship. It is common in Indigenous communities to have someone who has established relationships to work with youth. This is part of the collective value that is given to elders and youth workers who are already known by families. 
We gathered many stories told by the youths while engaged in hiking, camping, and being on the land. The anecdotes and stories were mainly oral and recounted in memory, while some of them were documented in video and transcribed, with permission. In the third year of the project, we decided to engage in digital storytelling, working with a specific group of youths and adults on a voluntary basis.

Over the whole project, we came to identify some aspects that seem to have a role in building strength and resilience in these youths and in the larger group. For example, learning about traditional cultural practices sensitised all of us to take care of each other in our relationships as co-researchers, and youths to take care of each other in their shared activities.

\section{Culture and Wellness}

I think the culture and everything is so beautiful, and how we're all working together in a collective. And the other thing I like too ... what matters is what you do, and the First Nations way is who are you, where are you from. (YCPO4)

Culture is viewed as a fundamental resource for Indigenous communities. While the notion of cultural continuity and identity is debated by some, a number of scholars see it as valuable, in the effort to revive and preserve the connection between past, present, and future. More specifically, Chandler and Lalonde (2009) connect cultural continuity, (i.e. the preservation of traditions, the land, beliefs, and language) with suicide prevention. The premise of this work is that knowing and practicing one's culture is connected to wellness and this is the basis of cultural continuity and suicide prevention. Retaining and strengthening cultural roots and practices is viewed as a means to maintaining community culture and strength.

Carlson (2010) and Chandler and Lalonde (1998) suggest that cultural connection and continuity are key in preventing self-harm among Indigenous youths; other studies highlight the importance of self determination (Kirmayer, Gone, \& Moses, 2014) and self-governance, use of traditional/original language, and re-discovering everyday customs that may have been lost due to cultural annihilation and genocide. Re-learning customs and culture receive concerted efforts by Indigenous communities, by investing in elders and cultural facilitators to promote the acknowledgement of a shared history and develop individual and collective identities (Kirmayer, MacDonald, \& Brass, 2001; Kulis, Robbins, Baker, Denetsosie, \& Deschine Parkhust, 2016). In this 
framework, cultural continuity is connected to a sense of belonging (Liebenberg, Ikeda, \& Wood, 2015), which is intended to contrast centuries of oppression and degradation.

Many elders in the communities we work with, are survivors of residential schools; where they were placed, as children, into schools for the purpose of eliminating their language and culture. The government of the time (1870s to 199 os in Canada, depending on the provinces) intended on completing assimilation through policy, and to punish individuals, families, and communities who practiced their cultural rituals and traditions (Dorrell, 2009; Truth and Reconciliation Commission of Canada, 2015). This was 'cultural genocide' for Indigenous peoples (Crichlow, 2002; Davidson, 2012). In order for healing to take place, it is widely accepted among the Indigenous communities that we engage in learning about culture and the land as a part of reclaiming Indigenous community, identity, and strength. It may be a complex and disputed truth, but our experience has revealed this is part of an understanding of cultural continuity.

The youth in our program live on reserve and therefore are mainly in contact with their Indigenous peers and friends. They talk about culture as they have participated in our project, and they sometimes state a lack of connection to the culture of their Nation; for example, a boy told us he had never spent time with an elder before, nor understood the role of ancestors. In the context of land-based activities, continuity means to re-discover and reinterpret the traditional notion of the land. Land is viewed as a primary connection, because the land provides food, water, housing, the idea of spirit, and connection to our own spirituality. This is how - in the traditional view - land provides culture; as such, it is a fundamental part of the traditional teachings of Indigenous peoples.

\section{Understanding the Storytelling Process}

Archibald (2018) recounts a pedagogical story for us to hear and begin new ways to see. In a story work workshop, we prepared to think differently about stories in the context of culture. Archibald (2008, 2018) tells us of Mr. Magpie and Mr. Crow, a children's story, where each bird seeks something for their community, but for different reasons, hence with different results. The lesson is about intentions, expectations, jealousy, and learning respect and rules. Stories can evoke different memories, ideas, and emotions. They would be told by elders to convey a lesson, so listeners can make sense of the story and use it in their own lives. The significance of the story is rooted in its origins, as it was told by the 
ancestors. In order to learn anything from it, we must be ready to listen, attend to our feelings, thoughts, and responses. Archibald (2008) also reminds us that the story is not a tidy narrative with a beginning, middle, and end.

Storytelling is situated within Indigenous epistemology and pedagogy, where knowledge has been passed on through oral traditions for centuries. For a non-Indigenous person, it is almost impossible to understand what this means, until we work on this aspect ourselves, in concrete relationships with the Indigenous peoples. The use of metaphors, animal stories, and pictures means that stories are told and understood quite differently than in Western pedagogy. I learned to accept stories as evolving, meant to help us developing our hearts, minds, and open ourselves to different ways of knowing. Storytelling sustains learning, remembering, understanding our selves, understanding others and the world: a reflexive, embodied, slow paced process that requires persistence and caring (Archibald, 2008).

As a research team, we prepared ourselves for this task by reading and taking workshops on storytelling and training on digital storytelling. We were challenged to think about, tell stories, and make sense of stories differently. I had some personal work to do. I considered my fears about telling a truthful story: would I be judged or believed? Preparation is as much a part of the journey as the storytelling itself, an activity extending beyond our thoughts or intellect. This includes developing trust, empathy, and self-understanding.

The nature of the story is grounded in a reflective ongoing space which is iterative. Past events become salient in the present when remembered. There is a flow of interaction and reconsideration; the process of discovery is key to the story work (West, 2001) and subjectivity takes precedence over objectivity. Discovery is neither Western nor Indigenous: it is a term that researchers might use to mark the human capacity to reconnect to knowledge, recognise and remember.

Indigenous principles of working with Indigenous peoples and storytelling typically refer to respect, reverence, responsibility, and reciprocity (Kovach, 2009), which are foundational to many Indigenous peoples (Carlson et al., 2018). Acknowledgment means taking time for valuing relationships which are a result of our work and the narrative. Indigenous story work is explicitly grounded in family, generations, community, nation, as well as the connection between the intellectual, spiritual, physical, and emotional (Archibald, 2008, 2018). This may be compatible with some forms of Western storytelling, when narratives are embodied and contextualised in cultural history, such as in the feminist tradition of exploring women's everyday lives (e.g. Last, 20o9; Steedman, 1987).

The historic, oppressive, and colonial context has led to the annihilation of Indigenous peoples' cultures in Canada (Truth and Reconciliation Commission, 2015). This history suggests that the new generations have limited ways to 
connect with the past. Some elders say that knowledge was 'put to sleep' when North American laws established residential schools for Indigenous children and placed them in care away from their families. Indigenous languages were eliminated, but some survivors of residential schools were able to reconstruct their memories and work with stories (Archibald, 2018).

A powerful reconnection occurs in relationships, when young people can access memories through elders and knowledge keepers who are familiar with the community history (Archibald, 2008) and the land. Indigenous stories rely on the collective as well as individual, the method is contextual and based on stimulating other stories, asking questions, and discussing issues. No story is isolated from the whole. Translation from traditional languages (e.g. Halq'eméylem, the language of the Stó:lō Peoples) is another key to rebuilding culture and making connections to the past. Language carries memories and history (Treuer, 2008).

Hence, Indigenous storytelling often begins with stories from elders and parents (Archibald, 2018). As with my father, it may be an everyday experience, but some parents may have to regain the ability to tell, if this was lost in the process of forced assimilation. The lessons from these stories are, like my father's story, not always obvious, as they use metaphors. We heard a cultural story of Coyote, a kind of trickster, enchanter, and magician, whose symbolism refers to an alchemic way of interpretation and making sense of the world (Archibald, 2008, 2018). By 'alchemic', I mean to signify that knowledge is more than material: it is also about the spirit, mind, and heart, that combine to create something new. The story of Coyote is also about seeing: he loses his eyes and has to find new ways of seeing (my interpretation) through grief and struggle. This metaphor of seeing is a meaningful lesson within Indigenous culture.

In our group gatherings with youth, we often started by talking about the land and what it means to us. Some participants began to recognise their connection to the land and its influence on them. In hikes and camps, most storytelling took place in groups, during and after an activity, such as working with cedar wood or walking by the river. These occasional and spontaneous stories took place throughout the project and are still ongoing. We were always ready to ask and listen about their connection to the land, and they responded in various ways, as in these three examples:

... I wasn't that much connected to the land until they got me singing and drumming. That's how I met all my friends and started connecting to the land even more. (Св $\mathrm{PO} 1)$

... I feel connected to the land by canoe pulling, being involved with smokehouse and stuff like travelling, singing for the new ones, and always living there. I think there is many more stuff to learn about the land. I 
don't think I've learned very much about the trees, ancestral land and the history. I feel connected with it by being out on the river fishing, catching a lot of fish, and I enjoy having fish and giving back to the river. When I was in school, I liked to carve, make carvings, paint onto the carvings. (СBPO2)

... I think I, too, am getting better at being connected with the land, in the sense of learning the oral history and the teachings that are connected with the land because I don't know it. I've been told those stories so many times, listened to an elder and hear the stories but it's not being retained. But I just think that having an open mind, like said, going to an elder and learning from their teachings, values that each elder brings .... (YCP15)

These narratives make explicit connections to their thoughts while they are engaged in activities. The narrators are generating their own interpretations of their experiences. Occasionally stories are not only told through words or oral history; they can be told by songs or drumming, carving or weaving. They teach us about our kinship with the mountains, trees, and the land.

\section{Digital Stories of Belonging}

Our workshop on digital storytelling was aimed at producing a digital story and led by an Indigenous facilitator. We started each day in a talking circle, considering a reflexive question, as is common to Indigenous ways of sharing. We then chose a story of our own and worked individually to record it, composing music, adding images, pictures, and words. Finally, the story was converted to a short video. All the participants, nine youth and four adults developed their work individually at first. Youth worked along side of each other. Some worked together in pairs or as a group after their initial work. Digital storytelling is intentionally built through a personal and interactive process, using technology to engage and assist participants in learning differently (Behmer, 2005).

Four youth completed their stories for sharing; one of them played his own guitar music for the soundtrack. The adults who attended the session also produced and shared their digital story, including myself. Youth and adults commented on the value of the workshop and added that they would have benefited from elders participating and modeling storytelling in the workshop. To enforce the principle that the stories belong entirely to the participants, we asked permission to share them, and all of the four youth participants who completed the video, gave their permission. The videos are three minutes long, 
so the written material is short and evocative; to understand it, we need to connect words with the audio-visual parts.

An example: One young man recounted how he spent his time on the reserve. This story is about celebrating togetherness and reconnecting to the community. It gives an idea of 'relational ecology', which is consistent with Indigenous epistemology. This young man lives on a small reserve of 300 people, a land occupied and owned solely by Indigenous peoples, which is referred to as the "rez".

... Community events - you get to hang out with your cousins and do any of the activities. Enjoy their company while it lasts. House gathering - this category is for the cousins you consider - like they are almost siblings. You go to their house and watch tv and play video games ... [we can] find remote locations for fort building. This is fun when you are able to make plans with your favourite rez friends or cousins. (DST PA)

Telling the story, this young man celebrates enlarged family (collective) bonds: the cousins are "almost siblings". By choosing these simple and normal activities for his digital story, he signals that they are important. Most of his narrative refers to an ecology of relationships. He refers to being in the woodlands, the sounds of nature, and the modern sounds of rap music - all part of his living on the reserve.

The second example is about a young man and intergenerational family support and protection, as well as fears and vulnerability:

... I was laying on the couch one night and I was crying .... I said that I was afraid of being homeless. She (my Mom) reassured me that I would never be homeless .... It was only a few months after this that she told me I would be living with my Dad. My dad had just moved back in with my grandpa after my grandma passed away. So I would be living with him too. I loved this idea. I love my grandpa to death so that was awesome. (DST PJ)

Intergenerational bonds between family men are palpable here. His story began with his mother but evolved into talking about his father and grandfather. His sense of belonging is connected with a feeling of solace and not being alone. The visual for this part of the story is a photo of the young man, his father and grandfather, wearing fatigues (i.e. green-brown camouflage wear), sitting on a log, and holding their rifles. They would go hunting together as a family activity. The story of this young man resonated with others in the workshop, 
who thought about their parents and grandparents, about historical loss of family members (e.g. mother in this case), and how support evolved from the 'doing' activities together. This evoked tears in some of the participants.

All of the shared stories in the workshop are resonant with ecological land based, and potentially healing, connections to family, community, and friends. The workshop did this in two ways, by working on the stories in the workshop individually and together, and by completing the story. Their writing, thinking and oral process was talked about at the end of the day. The completion of the digital story was a source of pride, by doing something in a new way.

In the final reflective circle, we talked about how the workshop affected all of us. The young adults and youth said that it was good to share their story, making connections among us, and being able to take their own story away with them, to share with others. This gave them control over their own story. One youth posted his story on YouTube. Another was going to share it with his family immediately. We believe that the workshop was a shared giving, where the participants went away with a sense of their own power, ability to learn, and express themselves uniquely.

Storytelling can be a way of reclaiming the self and a decolonising process. Storytelling allowed us to enforce a shared, intergenerational, and culture-bond process among the youth, with adults, elders, and within the larger community. In this chapter, I have described how working with culture obliges the researcher to interrogate herself and that the process was informed by Indigenous epistemologies. I believe that in this project, storytellers took ownership of their words in the creation of narratives. The process seemed to change self-perceptions, or at least the capacity of participants to share and reflect. Based on what we experienced ourselves in the training, land activities, and workshops, we started to feel a building sense of connection to each other and to the community.

A relevant issue in cultural work is that we academics are not experts in any way. Instead, the real expertise lies with the youth and their elders in the community. Academics are knowledge seekers, so can bring a difference, especially if we do this with the permission and agreement of Indigenous communities. This kind of dialogue requires searching for a respectful, reciprocal, and collaborative relationship. Relationships are key in the work that we are engaged in, while becoming and working in Indigenous communities. Relationships are the reality and the fundament of lived experience of Indigenous peoples (Wilson, 2008). Thus, the story could only 
be created as a result of the relationships we have with elders, other youth, and the research team. Elders represent the roots of the storytelling process because they model how and why to tell the stories, by telling stories in circle, by using generative metaphors and symbols, like in using animal stories. In the process described, researchers also influence the storytelling, because of their positionality and by their active presence in the room or land where the stories are told. They are not neutral spectators, they tell stories too, and by suggesting new ways of doing - for example, using technology in the digital storytelling workshop - they bring discontinuity in the process.

This project and the storytelling process remains ongoing. As it has evolved, we have changed our expectations and interpretation of our work with these youth, their culture and sense of belonging. The premise at the centre of this work is that (re)connecting to our environment is part of our identity and belonging. Stories about the land and family bonds can support a stronger sense of belonging and wellbeing within the cultural context. Hopefully, this will also strengthen a sense of freedom: when you have real roots, you know that you always know where home is.

I respectfully acknowledge that these descriptors, perspectives of meaning, and interpretations are mine, as a researcher, and these may not be the ways in which the participants would describe the same process. Central to the work here described is an Indigenous methodology which means acting to decolonise rather than colonise. I am aware of the work I had to do, to set aside my cultural and biographical roots and habits, to be able to learn from another epistemological perspective. The researcher's words and interpretations of a story, or situation, might be given to the participants in order to bring the cultural dialogues to another level. However, this would only be done with a trusting communication relationship that would allow for such feedback or interpretation. Metalevel communication occurred, but was not part of the explicit project goals or analysis. It is important for us to maintain relationships over analysis. The struggle to avoid colonisation is not an easy one.

I conclude by writing "all my relations", a traditional Indigenous phrase used to acknowledge the connections we have with each other, as parts of universal relationships, and having reciprocal responsibility (King, 199o). The phrase suggests the ecology of our interactions.

\section{Acknowledgement}

This research was made possible by funding from the Canadian Institutes Health Research Grant \#33785. 


\section{References}

Alfred, G. T. (2009). Colonialism and state dependency. Journal of Aboriginal Health, $5(2), 42-6$ o.

Archibald, J. (2008). Indigenous storywork: Educating the heart, mind, body, and spirit. University of British Columbia Press.

Archibald, J. (2018, January 15). Storyworks, storytelling. Workshop at Stó:lō Nation, Chilliwack, B.C., Canada.

Behmer, S. (2005). Literature review: Digital storytelling: Examining the process with middle school students [Unpublished literature review]. Iowa State University. http://citeseerx.ist.psu.edu/viewdoc/download?doi=10.1.1.452.6410\&rep= repı\&type $=$ pdf

Carlson, K. T. (2010). The power of place, the problem of time: Aboriginal identity and historical consciousness in the cauldron of colonialism (2nd ed.). University of Toronto Press.

Carlson, K. T., Lutz, J. S., Schaepe, D. M., \& Naxaxalhts'i (McHalsie, A. S.) (Eds.). (2018). Towards a new ethnohistory. University of Manitoba Press.

Chan, A. S. (2017, March). The decolonizing and the Indigenizing discourse [Paper presentation]. European Society for Research on the Education of Adults Conference, Aarhus University, Copenhagen, Denmark.

Chandler, M. J., \& Lalonde, C. (1998). Cultural continuity as a hedge against suicide in Canada's First Nations. Transcultural Psychiatry, 35(2), 191-219.

Chandler, M. J., \& Lalonde, C. (2008). Cultural continuity as a protective factor against suicide in First Nations youth. Horizons - A Special Issue on Aboriginal Youth, Hope or Heartbreak: Aboriginal Youth and Canada's Future, 10(1), 68-72.

Corntassel, J., Chaw-win-is, \& T'lakwadzi. (2009). Indigenous storytelling, truth-telling, and community approaches to reconciliation. English Studies in Canada, 35(1), 137159.

Crichlow, W. (2002). Western colonization as disease: Native adoption \& cultural genocide. Critical Social Work, 3(1), 1-14.

Davidson, L. (2012). Cultural genocide. Rutgers University Press.

Dorrell, M. (2009). From reconciliation to reconciling: Reading what "we now recognize" in the Government of Canada's 2008 residential schools apology. English Studies in Canada, 35(1), 27-45. doi:10.1353/esc.o/o165

Jensen, D. F. N. (2006). Metaphors as a bridge to understanding educational and social contexts. International Journal of Qualitative Methods, 5(1), 2-17.

King, T. (1990). All my relations. McClellend \& Stewart.

Kirmayer, L. J., Brass, G. M., Holton, T., Paul, K., Simpson, C., \& Tait, C. (2007). Suicide among Aboriginal people in Canada. Aboriginal Healing Foundation. 
Kirmayer, L. J., Gone, J. P., \& Moses, J. (2014). Rethinking historical trauma. Transcultural Psychiatry, 51(3), 299-319.

Kirmayer, L. J., MacDonald, M. E., \& Brass, G. M. (Eds.). (2001). The mental health of Indigenous people. McGill University.

Kovach, M. (2009). Indigenous methodologies. University of Toronto Press.

Kulis, S. S., Robbins, D. E., Baker, T. M., Denetsosie, S., \& Deschine Parkhurst, N. A. (2016). A latent class analysis of urban American Indian youth identities. Cultural Diversity and Ethnic Minority Psychology, 22(2), 215-228.

Last, N. (2009). Nella Last's war: The Second World War diaries of housewife 49 (R. Broad \& S. Fleming, Eds.). Profile Books.

Liebenberg, L., Ikeda, J., \& Wood, M. (2015). "It's just part of my culture”: Understanding language and land in the resilience processes of Aboriginal youth. In L. L. Theron \& M. Ungar (Eds.), Youth resilience and culture: Commonalities and complexities (pp. 105-116). Springer Netherlands.

McAslin, W. D. (2005). Justice as healing: Indigenous ways. Living Justice Press.

Said, E. W. (1978). Orientalism. Pantheon Books.

Smith, L. T. (2012). Decolonizing methodologies (2nd ed.). Zed Press.

Steedman, C. K. (1987). Landscape for a good woman. Rutgers University Press.

Treuer, A. (2008). Living our language: Ojibwe tales and oral histories. Minnesota Historical Society Press.

Truth and Reconciliation Commission of Canada. (2015). Calls to action. Government of Canada.

West, L. (2001). Doctors on the edge. Free Association Books.

Wilson, S. (2008). Research is ceremony. Fernwood Press. 